\title{
Neurocognitive interventions based on network neuroscience may break the cycle of drug addiction relapse
}

Kavinash Loganathan ${ }^{1}$ and Eric Tatt Wei Ho ${ }^{1,2, *}$

${ }^{1}$ Center for Intelligent Signal \& Imaging, Universiti Teknologi PETRONAS, Perak, Malaysia.

${ }^{2}$ Department of Electrical \& Electronics Engineering, Universiti Teknologi PETRONAS, Perak, Malaysia.

* Correspondence: hotattwei@utp.edu.my; Tel.: +60-5-368-7899

Received: 2 April 2020; Accepted: 13 May 2020; Published: 30 May 2020

Edited by: King-Hwa Ling (Harvard Medical School, MA, USA)

Reviewed by: Zurina Hassan (Universiti Sains Malaysia, Malaysia); Ruben Pérez-Elvira (NEPSA Rehabilitacion Neurologica, Spain); Siti Rafidah Yusof (Universiti Sains Malaysia, Malaysia)

https://doi.org/10.31117/neuroscirn.v3i2.48

\begin{abstract}
In Malaysia, abstinence-centric programs failed to reduce drug use and stem the spread of HIV. The Malaysian government shifted its focus to implement harm reduction strategies with methadone maintenance therapy (MMT), in particular proving to be effective in improving the overall health and wellbeing of people who inject drugs (PWIDs). Despite this success, MMT retention rates remain low, as methadone is only able to stall drug consumption, but not stop it completely. Neuroimaging research revealed that PWIDs enrolled in MMT still display addictive behavior, including drug cue sensitivity, craving, and withdrawal, despite treatment adherence. Brain activity amongst treated PWIDs continues to bear similarities to untreated individuals, as they struggle with cognitive impairments and poor self-control. Findings from the emerging field of network neuroscience could provide fresh insight into the mechanics of addiction, especially the impact of substance abuse on brain-wide cognitive networks. Concurrently, the development of non-intrusive cognitive interventions, such as neurofeedback and transcranial magnetic stimulation, shows promise to reprogram a person's patterns of brain activity, including those regulated by large-scale networks, to a state resembling normalcy. We highlight the importance of relapse in the life-long rehabilitation of substance abuse. The lack of treatment options to handle relapse after successful harmreduction policies is due to the absence of a conceptual framework to reason about interventions. We review recent research in the new field of network neuroscience, which suggests that altered brain activity due to drug addiction underlies the propensity for relapse and that this dysfunction is not addressed in drug rehabilitation programs. We hypothesize that non-invasive, non-pharmacological cognitive interventions based on network neuroscience to correct brain activity dysfunction associated with addiction are potential therapies to treat drug addiction relapse. In complement with medicine-substitution-based therapies, we hope this approach will finally break the cycle of addiction.
\end{abstract}

Keywords: addiction relapse; network neuroscience; cognitive intervention; pharmacological substitution therapy; drug addiction

C2020 by Loganathan \& Ho for use and distribution in accord with the Creative Commons Attribution (CC BY-NC 4.0) license (https://creativecommons.org/licenses/by-nc/4.0/), which permits unrestricted non-commercial use, distribution, and reproduction in any medium, provided the original author and source are credited.

\subsection{BACKGROUND}

Malaysia's approach to drug addict rehabilitation shifted in 2005 from a policy of total abstinence in controlled environments towards a harm reduction approach (Vicknasingam and Mahmud, 2008) to stem the burgeoning HIV epidemic in the country as people who inject drugs (PWID) comprise $66 \%$ of all HIV cases in Malaysia (Ali et al., 2018). The Harm Reduction 
program comprising of needle syringe and exchange program (NESP), condom distribution, and methadone maintenance therapy (MMT), was initially carried out by non-governmental organizations, medical practitioners and was shown to avert HIV infections effectively. The program has been expanded significantly to include deployment at the National Anti-Drug Agency (NADA) and prison levels (Naning et al., 2014). MMT has demonstrated efficacy at reducing both heroin consumption and associated risky behaviors (Wegman et al., 2017). The Malaysian Methadone Treatment Outcome cross-sectional study involving 3254 respondents from 103 treatment centers in Malaysia established that MMT significantly improved reintegration of former-people who inject drugs (PWIDs) into normative living patterns, with $66 \%$ of patients working salaried jobs and experiencing an overall increased quality of life (Ali et al., 2018).

Since opiates are abused in $75 \%$ of drug-taking cases in Malaysia (Chie et al., 2015), MMT has significant potential to ameliorate the drug problem in Malaysia via rehabilitation. As a therapy, MMT is a corrective rather than curative, employing pharmacological substitution of opioids with methadone (Baharom et al., 2012) to relieve physical discomfort and pain arising from narcotic withdrawal and to block the euphoric effects of drugs (Joseph et al., 2000). However, long-term adherence to MMT, a key factor in the overall success of this therapy, is poor with a retention rate of $\sim 20$ to $60 \%$ in Malaysia (Ramli et al., 2012; Wickersham et al., 2013) due to various socio-cultural-economic factors (Mukherjee et al., 2016). In Malaysia, the long-term economic sustainability of MMT programs is also questionable because public funds heavily subsidize methadone costs at RM58.2 million (USD 14.2 million) to treat 65,259 opioid dependents from 2006 to 2013 (Naning et al., 2014).

Not-withstanding the success at curtailing HIV spread, there is a lack of evidence that the drug rehabilitation programs successfully reintegrate former-PWIDs into society in a sustainable way. Early reports estimated drug relapse rates between $70-90 \%$ within the first year of rehabilitation (Mazlan et al., 2006) with $20-40 \%$ of PWIDs seeking rehabilitation at NADA Cure \& Care Centres between 2013-2017 were registered, relapsed users (Statistics of Drug Addicts by Case Studies, National Anti-drug Agency, Ministry of Home Affairs Malaysia). Worldwide, there is emerging evidence that MMT only delays addictive drug-taking behavior in a dose-dependent manner (Donny et al., 2002; Wickersham et al., 2013) but does not significantly reduce incidents of relapse back into chronic drug use (Clark et al., 2014). Studies of rehabilitating PWIDs enrolled in MMT programs reported increased drug craving just before regular methadone administration (llgen et al., 2008), the persistence of craving even after receiving stable doses (Strasser et al., 2010) and continued use of illicit substances to cope with the physical and psychological symptoms of withdrawal (Naji et al., 2016). At best, MMT acts as a temporary respite to deal with craving and withdrawal symptoms but does little in the way of returning a recovering addict to sustained cognitive and behavioral normalcy.

\subsection{A transient solution: Neuroimaging evidence of methadone's limitations}

Neuroimaging studies report that MMT prolongs drug dependence and maintains the addicted state of the brain even after the completion of an MMT rehabilitation program ( $\mathrm{Ma}$ et al., 2011). The brain continues to be primed, retaining responsiveness to drug cues (Langleben et al., 2008) that reinforce the desire for, and dependence on opioids as inhibitory cognitive control is overridden (Zhang et al., 2017). MMT-enrolees struggle to accomplish mundane, nondrug-related tasks (Marvel et al., 2012), exhibiting impaired goal-directed behavior (Li et al., 2015), and consequently increased levels of frustration and stress, thus intensifying cravings (Marvel et al., 2012).

Brain activity measurements are taken just before MMT commencement and again after 12 months of treatment revealed no change in brain reward circuitry, behavioral control, and error occurrence, despite treatment adherence (Ye et al., 2018), as patterns of brain activity after methadone administration simply mirrors that of untreated heroin consumption (Wang et al., 2016). Drug-related cognitive and emotional impairments persist amongst drug users treated with MMT (Marvel et al., 2012), including enhanced drugrelated memory processing, manifesting salient emotional responses to drugs (Chang et al., 2016) and dysfunctional valuations of drug cues. This aberrant processing elevates the importance of opioids over nondrug-related rewards and biases a PWIDs' decisionmaking towards drug-taking tendencies (Gradin et al., 2014).

Unable to disassociate from intrusive thoughts of opioids and consumption-related cues, drug users on MMT are at risk of relapse (Li et al., 2018). It appears that methadone does not alter the neurological basis of craving and addiction (Tau et al., 2014) but only displaces opioids as the object of dependence, sans 
pleasure (Ma et al., 2011). Indeed, PWIDs undergoing MMT face the greatest risk of relapse at the end of a 24hour inter-dose period (Langleben et al., 2008). Taking a longer view, studies featuring 6- and 12-month followup measurements in relapsed MMT patients revealed continued abnormal attentional responses to, and increased valuation of, rewards, impaired reward expectation, debilitated inhibitory control, and dysfunctional decision-making, compared to healthy controls (Chang et al., 2016). Methadone alone was not enough to offset the dysfunction to brain circuitry that had developed as a result of prior sustained opioid use.

\subsection{Cognitive interventions from network neuroscience may complement MMT for efficacious rehabilitation}

Methadone therapy has undisputed and demonstrable benefits from public health and socioeconomic standpoint as it effectively reduces HIV transmission, risk-taking behavior, self-reported criminal activities, and mortality while improving employment rates among opioid PWIDs (Musa et al., 2012). However, MMT alone does not nullify the sensation of craving and drug-linked impairment of cognitive function and reward valuation in the brain. New interventions must jointly complement methadone to make rehabilitation sustainable and prevent relapse. Solving this problem requires an understanding of how to reverse cravings and the overriding impulsive and compulsive decision to take drugs, which perpetuates the dependence of PWIDs on drugs.

Recent advances in network neuroscience provide novel insights into the reconfiguration of brain activity patterns that accompany chronic drug use, hinting at novel interventions to restore normative cognitive activity. Network neuroscience is an emerging discipline studying the relationship between patterns of coordinated neural activity in the brain with mental function (Bassett and Sporns, 2017), augmenting the brain disease model of addiction (Volkow et al., 2016) with new scientific concepts for analyzing the functional dimension accompanying the physiological and molecular changes induced by habitual drug-taking. Studies from neuroimaging measurements using functional Magnetic Resonance Imaging (fMRI) revealed unique patterns of coordinated blood-flow (Fox and Raichle, 2007) from a network of brain regions that correspond to various cognitive tasks such as executive behavioral control (Seeley et al., 2007) and reward valuation (van den Bos and McClure, 2013). Disruptions in integrity or abnormality activity in these networks of neural agents within the brain have been linked to neuropsychiatric disorders, including addiction (Wang et al., 2018).

Introspective, attentional, and memory-based brain networks are subverted to focus on, and reinforce, the pleasurable effects of drug-taking (Evans and Cahill, 2016), with reduced activation occurring after drug consumption (Sutherland et al., 2012). However, in the absence of drugs, craving is triggered by drug-linked visual or sensory cues (Ekhtiari et al., 2016) that cause emotional distress. These cues are elevated to importance within the addicted brain as salient internal and external stimuli that need to be acted on for relief and suppression of craving (Janes et al., 2015). Concomitant to greater attention towards drug cues induced by accumulation of stressful mental states, the valuation-control (VC) network (van den Bos and McLure, 2013) becomes disproportionately activated (Xie et al., 2014). This elevates the value of opioids and encourages the pursuit of drugs (Zou et al., 2015) to the exclusion of other positive goal-directed behaviors (Janes et al., 2015). In healthy non-PWIDs, the valuation and control elements of the VC compete amongst themselves to maintain a balanced mindset. If impulsive behavioral choices are being considered, the control element exerts more influence to provide a measure of self-control. However, amongst non-treated heroin users, a bias towards heroin consumption and the almost complete suppression of the control element occurs, resulting in the impulsive, all-consuming drive for drugs (Zhai et al., 2015). Recovering PWIDs on methadone still display impaired self-control (Wang et al., 2018), suggesting that methadone is unable to assist in re-balancing the valuation-control network. Consequently, repeated craving-induced cyclical stimulations of emotional, attentional, and valuation networks will trigger memory networks to program habitual activation of these brain patterns, which then manifest as the urge to consume drugs during times of duress (Belin et al., 2013).

Here is an opportunity for new interventions, specifically addressing relapse in the rehabilitation of chronic drug dependents. The activation of brain attention and valuation networks in rehabilitating drug PWIDs might be reprogrammed to mute responsiveness to drug cues, thereby attenuating craving and the value of drugs perceived by the brain. MMT will still be an essential prerequisite to brain network activity reprogramming, as it can reduce emotional distress (Teoh et al., 2016), making the brain more amenable to neurocognitive reprogramming (Rezapour et al., 2017). We, therefore, advocate the joint implementation of 
neurocognitive interventions in tandem with existing methadone replacement therapies in Malaysia to provide a more holistic treatment plan when restoring normal cognitive function and prevent relapse. Such therapies do not involve the use of pharmaceuticals, relying instead on a patient's cognitive processes to reprogram the brain and break away from opioid dependencies. Examples of cognitive therapies include neurofeedback, mindfulness, and transcranial stimulation.

- Neurofeedback reduces drug-seeking symptoms while increasing abstinence duration by training the mind and body to act more optimally via improvements to emotive, cognitive, physical, and behavioral experiences (Dehghani-Arani et al., 2013). This method has been reported to successfully reprogram large-scale brain networks (Nicholson et al., 2018).

- Mindfulness is the systematic training of attention and self-control (Garland and Howard, 2018) to reduce stress as well as improve attention, emotional regulation, and cognitive performance across large-scale networks (Tang et al., 2017). Here, patients are encouraged to attend any thoughts, feelings, or sensations, without attempting to interfere with these ideas (Garland and Howard, 2018).

- Transcranial magnetic stimulation (TMS) is the non-invasive delivery of electric field pulses to the brain (Lazzaro et al., 2008) to facilitate long- and short-term neuronal and behavioral effects (Diana et al., 2017). This mode of therapy has been reported to reduce cocaine craving in PWIDs (Politi et al., 2008; Rapinesi et al., 2016; Shen et al., 2016) and inhibitory control (Bellamoli et al., 2014), possibly via its effects on dopamine and glutamate systems in the brain (Diana et al., 2017).

\subsection{Lack of MMT Efficacy in Amphetamine-type \\ Stimulant Users}

Amphetamine-type Stimulants (ATS) use is a growing problem in Malaysia (McKetin et al., 2008; United Nations Office on Drugs and Crimes, 2010) due to the high degree of co-use amongst opioid injectors (Chawarski et al., 2012; Desrosiers et al., 2016), with more than $60 \%$ of Malaysian opioid users also reporting a lifetime history of ATS use (Vicknasingam et al., 2010). Such co-use practices are considered a key contributing factor in the rise in HIV-positive cases as well as other infectious diseases in the country (Bachireddy et al., 2011; Chawarski et al., 2012; Choo et al., 2015), a situation already occurring in Israel (Bonny-Noach, 2019). Unfortunately, MMTs are not designed to support the treatment of ATS users (Zhang et al., 2015; Noori et al., 2016), with ATS-influenced disruptions to MMT programs reported in China (Zhang et al., 2019) and Romania (Alexandrescu, 2017). In fact, ATS use amongst Malaysian MMT participants may reduce the efficacy of the program as a means of rehabilitation (Singh et al., 2013). Thus far, there have been no reports of neurofeedback therapy on ATS users. However, initial research utilizing mindfulness- (Magor-Blatch, 2013; Magor-Blatch et al., 2014) and TMS-based therapies (Wu et al., 2018) appear promising, reducing the addictive pull of ATS. However, too few studies highlighting the effects of neurocognitive therapies on ATS users.

\subsection{HYPOTHESIS}

Non-pharmacological neurocognitive intervention therapies may repattern brain functional network activity in rehabilitated drug users to treat the potential for relapse into addiction. In combination with medicine-substitution therapy, these therapies form a complete and sustainable treatment to rehabilitate drug addiction in a sustained manner in PWIDs, including users co-administering opioids and ATS.

Acknowledgments: ETWH thanks the Ministry of Higher Education, Malaysia for funding support through the Higher Institution Center of Excellence (HI-CoE) program awarded to the Center for Intelligent Signal \& Imaging Research (CISIR), Universiti Teknologi PETRONAS. All authors thank the Yayasan Universiti Teknologi PETRONAS for funding through the Fundamental Research Grant (YUTP-FRG).

Author Contributions: K.L. conceived the paper. K.L and E.T.W.H developed the hypothesis, arguments and wrote the paper.

Conflicts of Interest: The authors declare no conflict of interest.

\section{References}

Alexandrescu, L. (2017). NPS and the methadone queue: Spillages of space and time. International Journal on Drug Policy, 40, 50-56. https://doi.org/10.1016/i.drugpo.2016.09.009

Ali, N., Aziz, S. A., Nordin, S., Mi, N. C., Abdullah, N., Paranthaman, V., Mahmud, M., Yee, A., \& Danaee, M. (2018). Evaluation of methadone treatment in malaysia: findings from the Malaysian methadone treatment outcome study (MyTOS). Substance Use \& Misuse, 53(2), 239-248. https://doi.org/10.1080/10826084.2017.1385630 
Bachireddy, C., Bazazi, A. R., Kavasery, R., Govindasamy, S., Kamarulzaman, A., \& Altice, F. L. (2011). Attitudes toward opioid substitution therapy and pre-incarceration HIV transmission behaviors among HIV-infected prisoners in Malaysia: implications for secondary prevention. Drug and Alcohol Dependence, 116(1-3), 151-157. https://doi.org/10.1016/j.drugalcdep.2010.12.001

Baharom, N., Hassan, M. R., Ali, N., \& Shah, S. A. (2012). Improvement of quality of life following 6 months of methadone maintenance therapy in Malaysia. Substance Abuse Treatment, Prevention, and Policy, 7, 32. https://doi.org/10.1186/1747-597X-7-32

Bassett, D. S., \& Sporns, O. (2017). Network neuroscience. Nature Neuroscience, 20(3), 353-364. https://doi.org/10.1038/nn.4502

Belin, D., Belin-Rauscent, A., Murray, J. E., \& Everitt, B. J. (2013). Addiction: failure of control over maladaptive incentive habits. Current Opinion in Neurobiology, 23(4), 564-572. https://doi.org/10.1016/i.conb.2013.01.025

Bellamoli, E., Manganotti, P., Schwartz, R. P., Rimondo, C., Gomma, M., \& Serpelloni, G. (2014). rTMS in the treatment of drug addiction: an update about human studies. Behavioural Neurology, 2014, 815215. https://doi.org/10.1155/2014/815215

Bonny-Noach, H. (2019). Harm reduction drug policy in Israel: what has been accomplished and what still needs to be done? Israel Journal of Health Policy Research, 8(1), 75. https://doi.org/10.1186/s13584-019-0343-3

Chang, H., Li, W., Li, Q., Chen, J., Zhu, J., Ye, J., Liu, J., Li, Z., Li, Y., Shi, M., Wang, Y., \& Wang, W. (2016). Regional homogeneity changes between heroin relapse and non-relapse patients under methadone maintenance treatment: a resting-state fMRI study. BMC Neurology, 16(1), 145. https://doi.org/10.1186/s12883-016-0659-3

Chawarski, M. C., Vicknasingam, B., Mazlan, M., \& Schottenfeld, R. S. (2012). Lifetime ATS use and increased HIV risk among not-in-treatment opiate injectors in Malaysia. Drug and Alcohol Dependence, 124(1-2), 177-180. https://doi.org/10.1016/i.drugalcdep.2011.12.024

Chie, Q. T., Tam, C. L., Bonn, G., Wong, C. P., Dang, H. M., \& Khairuddin, R. (2015). Drug abuse, relapse, and prevention education in malaysia: perspective of university students through a mixed methods approach. Frontiers in Psychiatry, 6, 65. https://doi.org/10.3389/fpsyt.2015.00065

Choo, M. K. K., El-Bassel, N., Adam, P. C. G., Gilbert, L., Wu, E., West, B. S., Bazazi, A. R., De Wit, J. B. F., Ismail, R., \& Kamarulzaman, A. (2015). Prevalence and Correlates of HIV and Hepatitis C Virus Infections and Risk Behaviors among Malaysian Fishermen. PloS One, 10(8), e0118422. https://doi.org/10.1371/journal.pone.0118422

Clark, C. B., Hendricks, P. S., Lane, P. S., Trent, L., \& Cropsey, K. L. (2014). Methadone maintenance treatment may improve completion rates and delay opioid relapse for opioid dependent individuals under community corrections supervision. Addictive Behaviors, 39(12), 1736-1740. https://doi.org/10.1016/i.addbeh.2014.07.011

Dehghani-Arani, F., Rostami, R., \& Nadali, H. (2013). Neurofeedback training for opiate addiction: improvement of mental health and craving. Applied Psychophysiology and Biofeedback, 38(2), 133-141. https://doi.org/10.1007/s10484-013$\underline{9218-5}$

Desrosiers, A., Chooi, W.-T., Zaharim, N. M., Ahmad, I., Mohd Yasin, M. A., Syed Jaapar, S. Z., Schottenfeld, R. S., Vicknasingam, B., \& Chawarski, M. C. (2016). Emerging Drug Use Trends in Kelantan, Malaysia. Journal of Psychoactive Drugs, 48(3), 218-226. https://doi.org/10.1080/02791072.2016.1185553

Diana, M., Raij, T., Melis, M., Nummenmaa, A., Leggio, L., \& Bonci, A. (2017). Rehabilitating the addicted brain with transcranial magnetic stimulation. Nature Reviews. Neuroscience, 18(11), 685-693. https://doi.org/10.1038/nrn.2017.113

Donny, E. C., Walsh, S. L., Bigelow, G. E., Eissenberg, T., \& Stitzer, M. L. (2002). High-dose methadone produces superior opioid blockade and comparable withdrawal suppression to lower doses in opioid-dependent humans. Psychopharmacology, 161(2), 202-212. https://doi.org/10.1007/s00213-002-1027-0

Ekhtiari, H., Nasseri, P., Yavari, F., Mokri, A., \& Monterosso, J. (2016). Neuroscience of drug craving for addiction medicine: From circuits to therapies. Progress in Brain Research, 223, 115-141. https://doi.org/10.1016/bs.pbr.2015.10.002

Evans, C. J., \& Cahill, C. M. (2016). Neurobiology of opioid dependence in creating addiction vulnerability. F1000Research, 5. https://doi.org/10.12688/f1000research.8369.1

Fox, M. D., \& Raichle, M. E. (2007). Spontaneous fluctuations in brain activity observed with functional magnetic resonance imaging. Nature Reviews. Neuroscience, 8(9), 700-711. https://doi.org/10.1038/nrn2201

Garland, E. L., \& Howard, M. O. (2018). Mindfulness-based treatment of addiction: current state of the field and envisioning the next wave of research. Addiction Science \& Clinical Practice, 13(1), 14. https://doi.org/10.1186/s13722-018-0115-3

Gradin, V. B., Baldacchino, A., Balfour, D., Matthews, K., \& Steele, J. D. (2014). Abnormal brain activity during a reward and loss task in opiate-dependent patients receiving methadone maintenance therapy. Neuropsychopharmacology: Official Publication of the American College of Neuropsychopharmacology, 39(4), 885-894. https://doi.org/10.1038/npp.2013.289

Ilgen, M., Jain, A., Kim, H. M., \& Trafton, J. A. (2008). The effect of stress on craving for methadone depends on the timing of last methadone dose. Behaviour Research and Therapy, 46(10), 1170-1175. https://doi.org/10.1016/i.brat.2008.05.013

Janes, A. C., Farmer, S., Peechatka, A. L., Frederick, B. de B., \& Lukas, S. E. (2015). Insula-Dorsal Anterior Cingulate Cortex Coupling is Associated with Enhanced Brain Reactivity to Smoking Cues. Neuropsychopharmacology, 40(7), 1561-1568. 
https://doi.org/10.1038/npp.2015.9

Joseph, H., Stancliff, S., \& Langrod, J. (2000). Methadone maintenance treatment (MMT): a review of historical and clinical issues. Mount Sinai Journal of Medicine, 67(5-6), 347-364.

Langleben, D. D., Ruparel, K., Elman, I., Busch-Winokur, S., Pratiwadi, R., Loughead, J., O'Brien, C. P., \& Childress, A. R. (2008). Acute effect of methadone maintenance dose on brain FMRI response to heroin-related cues. American Journal of Psychiatry, 165(3), 390-394. https://doi.org/10.1176/appi.ajp.2007.07010070

Lazzaro, V. Di, Ziemann, U., \& Lemon, R. N. (2008). State of the art: Physiology of transcranial motor cortex stimulation. Brain Stimulation, 1(4), 345-362. https://doi.org/10.1016/i.brs.2008.07.004

Li, Q., Liu, J., Wang, W., Wang, Y., Li, W., Chen, J., Zhu, J., Yan, X., Li, Y., Li, Z., Ye, J., \& Wang, W. (2018). Disrupted coupling of large-scale networks is associated with relapse behaviour in heroin-dependent men. Journal of Psychiatry \& Neuroscience, 42(1), 48-57. https://doi.org/10.1503/ipn.170011

Li, W., Li, Q., Wang, D., Xiao, W., Liu, K., Shi, L., Zhu, J., Li, Y., Yan, X., Chen, J., Ye, J., Li, Z., Wang, Y., \& Wang, W. (2015). Dysfunctional default mode network in methadone treated patients who have a higher heroin relapse risk. Scientific Reports, 5, 15181. https://doi.org/10.1038/srep15181

Ma, N., Liu, Y., Fu, X.-M., Li, N., Wang, C.-X., Zhang, H., Qian, R.-B., Xu, H.-S., Hu, X., \& Zhang, D.-R. (2011). Abnormal brain default-mode network functional connectivity in drug addicts. PLoS One, 6(1), e16560. https://doi.org/10.1371/journal.pone.0016560

Magor-Blatch, L. (2013). Intervention for Amphetamine-type Stimulant (ATS) Use in the Therapeutic Community. University of New South Wales.

Magor-Blatch, L. E., Keen, J. L., \& Bhullar, N. (2014). Personality factors as predictors of programme completion of drug therapeutic communities. Mental Health and Substance Use, 7(2), 110-124. https://doi.org/10.1080/17523281.2013.806345

Marvel, C. L., Faulkner, M. L., Strain, E. C., Mintzer, M. Z., \& Desmond, J. E. (2012). An fMRI Investigation of Cerebellar Function During Verbal Working Memory in Methadone Maintenance Patients. Cerebellum, 11(1), 300-310. https://doi.org/10.1007/s12311-011-0311-0

Mazlan, M., Schottenfeld, R. S., \& Chawarski, M. C. (2006). New challenges and opportunities in managing substance abuse in Malaysia. Drug and Alcohol Review, 25(5), 473-478. https://doi.org/10.1080/09595230600883354

McKetin, R., Kozel, N., Douglas, J., Ali, R., Vicknasingam, B., Lund, J., \& Li, J.-H. (2008). The rise of methamphetamine in Southeast and East Asia. Drug and Alcohol Review, 27(3), 220-228. https://doi.org/10.1080/09595230801923710

Mukherjee, T. I., Wickersham, J. A., Desai, M. M., Pillai, V., Kamarulzaman, A., \& Altice, F. L. (2016). Factors associated with interest in receiving prison-based methadone maintenance therapy in Malaysia. Drug and Alcohol Dependence, 164, 120-127. https://doi.org/10.1016/j.drugalcdep.2016.04.037

Musa, R., Abu Bakar, A. Z., \& Ali Khan, U. (2012). Two-year outcomes of methadone maintenance therapy at a clinic in Malaysia. Asia-Pacific Journal of Public Health, 24(5), 826-832. https://doi.org/10.1177/1010539511404396

Naji, L., Dennis, B. B., Bawor, M., Plater, C., Pare, G., Worster, A., Varenbut, M., Daiter, J., Marsh, D. C., Desai, D., Thabane, L., \& Samaan, Z. (2016). A prospective study to investigate predictors of relapse among patients with opioid use disorder treated with methadone. Substance Abuse: Research and Treatment, 10, 9-18. https://doi.org/10.4137/SART.S37030

Naning, H., Kerr, C., Kamarulzaman, A., Osornprasop, S., Dahlui, M., Ng, C.-W., \& Wilson, D. P. (2014). Return on investment and cost-effectiveness of harm reduction program in Malaysia. Directions in development; human development. Washington, DC: World Bank Group. http://documents.worldbank.org/curated/en/310381468282285702/Return-oninvestment-and-cost-effectiveness-of-harm-reduction-program-in-Malaysia

Nicholson, A. A., Rabellino, D., Densmore, M., Frewen, P. A., Paret, C., Kluetsch, R., Schmahl, C., Theberge, J., Ros, T., Neufeld, R. W. J., McKinnon, M. C., Reiss, J. P., Jetly, R., \& Lanius, R. A. (2018). Intrinsic connectivity network dynamics in PTSD during amygdala downregulation using real-time $\mathrm{fMRI}$ neurofeedback: A preliminary analysis. Human Brain Mapping, 39(11), 4258-4275. https://doi.org/10.1002/hbm.24244

Noori, R., Daneshmand, R., Farhoudian, A., Ghaderi, S., Aryanfard, S., \& Moradi, A. (2016). Amphetamine-type stimulants in a group of adults in Tehran, Iran: a rapid situation assessment in twenty-two districts. Iranian Journal of Psychiatry and Behavioral Sciences, 10(4), e7704. https://doi.org/10.17795/ijpbs-7704

Politi, E., Fauci, E., Santoro, A., \& Smeraldi, E. (2008). Daily sessions of transcranial magnetic stimulation to the left prefrontal cortex gradually reduce cocaine craving. American Journal on Addictions, 17(4), 345-346.

https://doi.org/10.1080/10550490802139283

Ramli, M., Zafri, A. B., Junid, M. R., \& Hatta, S. (2012). Associated risk factors to non-compliance to methadone maintenance therapy. Medical Journal of Malaysia, 67(6), 560-564.

Rapinesi, C., Del Casale, A., Di Pietro, S., Ferri, V. R., Piacentino, D., Sani, G., Raccah, R. N., Zangen, A., Ferracuti, S., Vento, A. E., Angeletti, G., Brugnoli, R., Kotzalidis, G. D., \& Girardi, P. (2016). Add-on high frequency deep transcranial magnetic stimulation (dTMS) to bilateral prefrontal cortex reduces cocaine craving in patients with cocaine use disorder. Neuroscience Letters, 629, 43-47. https://doi.org/https://doi.org/10.1016/i.neulet.2016.06.049

Rezapour, T., Hatami, J., Farhoudian, A., Sofuoglu, M., Noroozi, A., Daneshmand, R., Samiei, A., \& Ekhtiari, H. (2017). 
Cognitive rehabilitation for individuals with opioid use disorder: A randomized controlled trial. Neuropsychological Rehabilitation, 1-17. https://doi.org/10.1080/09602011.2017.1391103

Seeley, W. W., Menon, V., Schatzberg, A. F., Keller, J., Glover, G. H., Kenna, H., Reiss, A. L., \& Greicius, M. D. (2007). Dissociable intrinsic connectivity networks for salience processing and executive control. Journal of Neuroscience, 27(9), 2349-2356. https://doi.org/10.1523/JNEUROSCl.5587-06.2007

Shen, Y., Cao, X., Tan, T., Shan, C., Wang, Y., Pan, J., He, H., \& Yuan, T.-F. (2016). 10-Hz repetitive transcranial magnetic stimulation of the left dorsolateral prefrontal cortex reduces heroin cue craving in long-term addicts. Biological Psychiatry, 80(3), e13-14. https://doi.org/10.1016/i.biopsych.2016.02.006

Singh, D., Chawarski, M. C., Schottenfeld, R., \& Vicknasingam, B. (2013). Substance abuse and the HIV situation in Malaysia. Journal of Food and Drug Analysis, 21(4), S46-S51. https://doi.org/10.1016/i.jfda.2013.09.033

Strasser, J., Wiesbeck, G. A., Meier, N., Stohler, R., \& Dursteler-Macfarland, K. M. (2010). Effects of a single $50 \%$ extra dose of methadone on heroin craving and mood in lower- versus higher-dose methadone patients. Journal of Clinical Psychopharmacology, 30(4), 450-454. https://doi.org/10.1097/JCP.0b013e3181e6df49

Sutherland, M. T., McHugh, M. J., Pariyadath, V., \& Stein, E. A. (2012). Resting state functional connectivity in addiction: Lessons learned and a road ahead. Neurolmage, 62(4), 2281-2295. https://doi.org/10.1016/i.neuroimage.2012.01.117

Tang, Y.-Y., Tang, Y., Tang, R., \& Lewis-Peacock, J. A. (2017). Brief Mental Training Reorganizes Large-Scale Brain Networks. Frontiers in Systems Neuroscience, 11, 6. https://doi.org/10.3389/fnsys.2017.00006

Tau, G. Z., Marsh, R., Wang, Z., Torres-Sanchez, T., Graniello, B., Hao, X., Xu, D., Packard, M. G., Duan, Y., Kangarlu, A., Martinez, D., \& Peterson, B. S. (2014). Neural correlates of reward-based spatial learning in persons with cocaine dependence. Neuropsychopharmacology, 39(3), 545-555. https://doi.org/10.1038/npp.2013.189

Teoh, B. F., J., Yee, A., Habil, M. H. B., \& Danaee, M. (2016). Effectiveness of methadone maintenance therapy and improvement in quality of life following a decade of implementation. Journal of Substance Abuse Treatment, 69, 50-56. https://doi.org/10.1016/i.jsat.2016.07.006

United Nations Office on Drugs and Crimes. (2010). World drug report. United Nations Publications.

van den Bos, W., \& McClure, S. M. (2013). Towards a general model of temporal discounting. Journal of the Experimental Analysis of Behavior, 99(1), 58-73. https://doi.org/10.1002/jeab.6

Vicknasingam, B., \& Mahmud, M. (2008). Malaysian drug treatment policy: An evolution from total abstinence to harm reduction. Malaysian Anti-Drugs Journal (Jurnal Antidadah Malaysia),(3), 107-121.

Vicknasingam, B., Mazlan, M., Schottenfeld, R. S., \& Chawarski, M. C. (2010). Injection of buprenorphine and buprenorphine/naloxone tablets in Malaysia. Drug and Alcohol Dependence, 111(1-2), 44-49. https://doi.org/10.1016/i.drugalcdep.2010.03.014

Volkow, N. D., Koob, G. F., \& McLellan, A. T. (2016). Neurobiologic advances from the brain disease model of addiction. New England Journal of Medicine, 374(4), 363-371. https://doi.org/10.1056/NEJMra1511480

Wang, L., Zou, F., Zhai, T., Lei, Y., Tan, S., Jin, X., Ye, E., Shao, Y., Yang, Y., \& Yang, Z. (2016). Abnormal gray matter volume and resting-state functional connectivity in former heroin-dependent individuals abstinent for multiple years. Addiction Biology, 21(3), 646-656. https://doi.org/10.1111/adb.12228

Wang, R., Li, M., Zhao, M., Yu, D., Hu, Y., Wiers, C. E., Wang, G.-J., Volkow, N. D., \& Yuan, K. (2018). Internet gaming disorder: deficits in functional and structural connectivity in the ventral tegmental area-Accumbens pathway. Brain Imaging and Behavior, 13, 1172-1181. https://doi.org/10.1007/s11682-018-9929-6

Wegman, M. P., Altice, F. L., Kaur, S., Rajandaran, V., Osornprasop, S., Wilson, D., Wilson, D. P., \& Kamarulzaman, A. (2017). Relapse to opioid use in opioid-dependent individuals released from compulsory drug detention centres compared with those from voluntary methadone treatment centres in Malaysia: a two-arm, prospective observational study. The Lancet. Global Health, 5(2), e198-e207. https://doi.org/10.1016/S2214-109X(16)30303-5

Wickersham, J. A., Zahari, M. M., Azar, M. M., Kamarulzaman, A., \& Altice, F. L. (2013). Methadone dose at the time of release from prison significantly influences retention in treatment: implications from a pilot study of HIV-infected prisoners transitioning to the community in Malaysia. Drug and Alcohol Dependence, 132(1-2), 378-382. https://doi.org/10.1016/j.drugalcdep.2013.01.005

Wu, X.-Q., Zan, G.-Y., Ju, Y.-Y., Chen, T.-Z., Guo, L.-B., Jiao, D.-L., Jiang, H.-F., Deng, Y.-Z., Liu, J.-G., \& Zhao, M. (2018). Lowfrequency repetitive transcranial magnetic stimulation inhibits the development of methamphetamine-induced conditioned place preference. Behavioural Brain Research, 353, 129-136. https://doi.org/10.1016/j.bbr.2018.07.004

Xie, C., Shao, Y., Ma, L., Zhai, T., Ye, E., Fu, L., Bi, G., Chen, G., Cohen, A., Li, W., Chen, G., Yang, Z., \& Li, S.-J. (2014). Imbalanced functional link between valuation networks in abstinent heroin-dependent subjects. Molecular Psychiatry, 19(1), 10-12. https://doi.org/10.1038/mp.2012.169

Ye, J.-J., Li, W., Zhang, D.-S., Li, Q., Zhu, J., Chen, J.-J., Li, Y.-B., Yan, X.-J., Liu, J.-R., Wei, X., Wang, Y.-R., \& Wang, W. (2018). Longitudinal behavioral and $\mathrm{fMRI}$-based assessment of inhibitory control in heroin addicts on methadone maintenance treatment. Experimental and Therapeutic Medicine, 16(4), 3202-3210. https://doi.org/10.3892/etm.2018.6571

Zhai, T., Shao, Y., Chen, G., Ye, E., Ma, L., Wang, L., Lei, Y., Chen, G., Li, W., Zou, F., Jin, X., Li, S.-J., \& Yang, Z. (2015). Nature of functional links in valuation networks differentiates impulsive behaviors between abstinent heroin-dependent subjects 
and nondrug-using subjects. Neurolmage, 115, 76-84. https://doi.org/10.1016/j.neuroimage.2015.04.060

Zhang, L., Bao, J., Harrington, A., Fan, X., Ning, Z., Zhang, J., Shi, D., Hu, M., Zhou, Z., Cai, Z., Zhao, M., \& Du, J. (2019). Mixed methods to explore factors associated with the decline of patients in the methadone maintenance treatment program in Shanghai, China. Harm Reduction Journal, 16(1), 34. https://doi.org/10.1186/s12954-019-0304-8

Zhang, X.-D., Kelly-Hanku, A., Chai, J.-J., Luo, J., Temmerman, M., \& Luchters, S. (2015). Sexual and reproductive health risks amongst female adolescents who use amphetamine-type stimulants and sell sex: a qualitative inquiry in Yunnan, China. Harm Reduction Journal, 12(1), 34. https://doi.org/10.1186/s12954-015-0065-y

Zhang, Y., Li, Q., Wen, X., Cai, W., Li, G., Tian, J., Zhang, Y. E., Liu, J., Yuan, K., Zhao, J., Wang, W., Zhou, Z., Ding, M., Gold, M. S., Liu, Y., \& Wang, G.-J. (2017). Granger causality reveals a dominant role of memory circuit in chronic opioid dependence. Addiction Biology, 22(4), 1068-1080. https://doi.org/10.1111/adb.12390

Zou, F., Wu, X., Zhai, T., Lei, Y., Shao, Y., Jin, X., Tan, S., Wu, B., Wang, L., \& Yang, Z. (2015). Abnormal resting-state functional connectivity of the nucleus accumbens in multi-year abstinent heroin addicts. Journal of Neuroscience Research, 93(11), 1693-1702. https://doi.org/10.1002/inr.23608 